\title{
High dietary zinc supplementation increases the occurrence of tetracycline and sulfonamide resistance genes in the intestine of weaned pigs
}

\author{
Wilfried Vahjen*, Dominika Pietruszyńska, Ingo C. Starke and Jürgen Zentek
}

\begin{abstract}
Background: Dietary zinc oxide is used in pig nutrition to combat post weaning diarrhoea. Recent data suggests that high doses ( $2.5 \mathrm{~g} / \mathrm{kg}$ feed) increase the bacterial antibiotic resistance development in weaned pigs. Therefore, the aim of this study was to investigate the development of enterobacterial antibiotic resistance genes in the intestinal tract of weaned pigs.

Findings: Weaned pigs were fed diets for 4 weeks containing 57 (low), 164 (intermediate) or 2425 (high) mg kg ${ }^{-1}$ analytical grade $\mathrm{ZnO}$. DNA extracts from stomach, mid-jejunum, terminal ileum and colon ascendens were amplified by qPCR assays to quantify copy numbers for the tetracycline (tetA) and sulfonamide (su/1) resistance genes in Gramnegative bacteria. Overall, the combined data $(n=336)$ showed that copy numbers for tetracycline and sulfonamide resistance genes were significantly increased in the high zinc treatment compared to the low (tetA: $p$ value $<10^{-6}$; sul1: $\mathrm{p}$ value $=1 \times 10^{-5}$ ) or intermediate (tetA: $\mathrm{P}<1.6 \times 10^{-4}$; sul1: $\left.\mathrm{P}=3.2 \times 10^{-4}\right)$ zinc treatment. Regarding the time dependent development, no treatment effects were seen 1 week after weaning, but significant differences between high and low/intermediate zinc treatments evolved 2 weeks after weaning. The increased number of tetA and sul 1 copies was not confined to the hind gut, but was already present in stomach contents.
\end{abstract}

Conclusions: The results of this study suggest that the use of high doses of dietary zinc beyond 2 weeks after weaning should be avoided in pigs due to the possible increase of antibiotic resistance in Gram-negative bacteria.

Keywords: Antibiotic resistance, Pig, Sulfonamide, Tetracycline, Zinc oxide

\section{Background}

In many countries high doses (up to $3000 \mathrm{mg} / \mathrm{kg}$ feed) of dietary zinc oxide are used in pig nutrition to successfully combat post weaning diarrhea in pigs, which is often induced by pathogenic Escherichia coli strains [1]. It has been shown that the intestinal microbiota of freshly weaned pigs is strongly perturbed by such high dietary zinc doses [2]. However, a direct inhibition of total enterobacteria or coliforms was not observed in several studies on this topic [3-5] and there are even indications that high dietary zinc may increase the diversity of

*Correspondence: Wilfried.Vahjen@fu-berlin.de

Institute of Animal Nutrition, Freie Universität Berlin, Berlin, Germany
Enterobacteriaceae [6]. Possibly connected to the hypothesis that dietary zinc enhances enterobacterial diversity is a recent report on the increased occurrence of multiresistant E. coli strains in pigs fed high zinc doses [7]. Although intrinsic resistances against certain antibiotics are known for Gram-negative bacteria, the lack of antibiotic use in the mentioned studies makes it much more likely that indeed zinc oxide is the determining factor for the observed increase in antibiotic resistances. These results are disconcerting, as enterobacteria are known to exchange genetic information frequently $[8,9]$. An increased spread of antibiotic resistance genes via horizontal gene transfer within the Enterobacteriaceae could lead to the emergence of strains with high virulence. 
The work by Bednorz et al. [7] showed a drastic zinc related increase $(18.6 \%)$ especially for tetracycline and sulfonamide resistant $E$. coli strains. The present study expands our knowledge on the relation between dietary zinc and antibiotic resistance by quantifying the occurrence of the tetracycline $(\operatorname{tet} \mathrm{A})$ and sulfonamide (sul 1 ) genes of Gram-negative bacteria regarding development and distribution of these genes in the intestinal tract of weaned pigs fed different amounts of dietary zinc during $6,13,20$ or 27 days post-weaning.

\section{Methods}

The study was conducted according to the German Animal Welfare Act (TierSchG) and approved by the local state office of occupational health and technical safety 'Landesamt für Gesundheit und Soziales, Berlin' (LaGeSo Reg. Nr. 0347/09). A total of 84 purebred German Landrace piglets $(7.2 \pm 1.2 \mathrm{~kg})$ from 10 sows of our Institute animal husbandry were weaned at $26 \pm 1$ days of age. Neither sows nor piglets received any antibiotic treatment. Sows and their offspring were kept in flatdeck pens in the same stable, the stable and pens were cleaned daily. No animal showed signs of disease during the trial period. From 12 days of age, piglets had access to a commercial non-medicated prestarter diet which was formulated to meet requirements of piglets with average body weight of 5-10 kg. After weaning, animals were randomly assigned to three treatment groups, kept in flatdeck pens with two animals per pen Weaned pigs were fed an antibiotic free commercial starter diet containing low $(57 \mathrm{mg} /$ $\mathrm{kg})$, intermediate $(164 \mathrm{mg} / \mathrm{kg})$ or high $(2,425 \mathrm{mg} / \mathrm{kg})$ zinc as analytical grade zinc oxide (Sigma Aldrich, Taufkirchen, Germany) to cover minimal to excessive dietary zinc supplementation.

On days 32, 39, 46 and 53 of life, seven pigs per group were euthanized $4 \mathrm{~h}$ after their last meal. The piglets were sedated with $20 \mathrm{mg} / \mathrm{kg} \mathrm{BW}$ of ketamine hydrochloride (Ursotamin ${ }^{\circledR}$, Serumwerk Bernburg AG, Germany) and $2 \mathrm{mg} / \mathrm{kg} \mathrm{BW}$ of azaperone (Stresnil ${ }^{\circledR}$, Jansen-Cilag, Neuss, Germany) prior to euthanasia with intracardial injection of $10 \mathrm{mg} / \mathrm{kg}$ BW of tetracaine hydrochloride, mebezonium iodide and embutramide $\left(\mathrm{T} 61^{\circledR}\right.$, Intervet, Unterschleißheim, Germany). Digesta contents were immediately shock-frozen in liquid nitrogen and stored at $-80{ }^{\circ} \mathrm{C}$ until further processing.

DNA extraction was performed with a commercial kit (Qiagen Stool kit, Qiagen, Hilden, Germany) with $200 \mathrm{mg}$ digesta according to the instructions of the manufacture except for an increase in temperature to $90{ }^{\circ} \mathrm{C}$ during the lysis step. DNA content in the extracts was quantified by fluorometric determination using a fluorospectrometer (ND3300, Thermo Scientific, Henningsdorf, Germany).
DNA concentration was adjusted to $50 \mathrm{ng} / \mu \mathrm{L}$ before PCR amplification.

Primers against tetA (tetA-1f: 5'-ATCATGCAAC TCGTCGGACA-3'; tetA1r: 5'-TCGTGTCCCAAT GAAAGCGA-3') and sul1 (sul1-3f: $5^{\prime}$-CGATCCGGGG ATGGGATTTT-3'; sul1-3r: 5'-CACCGAGACCAATA GCGGAA-3') for quantitative realtime PCR detection were generated from published sequences and validated against DNA from a range of positive and negative reference strains (see Additional file 1: Table S1). All primers were purchased from MWG Biotech (Straubing, Germany). A Stratagene MX3000p (Stratagene, Amsterdam, The Netherlands) was used for PCR amplification and fluorescent data collection. The master mix consisted of $12.5 \mu \mathrm{L}$ Brilliant II SYBR ${ }^{\circledR}$ Green QPCR Master Mix with Low ROX (Stratagene, Amsterdam, Netherlands), $0.5 \mu \mathrm{L}$ of each primer $(10 \mu \mathrm{M})$ and $10.5 \mu \mathrm{L}$ water. One microliter sample extract was added before PCR amplification $\left(1 \times 10 \mathrm{~min}\right.$ at $95^{\circ} \mathrm{C}$ followed by $40 \times 30 \mathrm{~s}$ at $95^{\circ} \mathrm{C}, 60 \mathrm{~s}$ at $60{ }^{\circ} \mathrm{C}$ and $60 \mathrm{~s}$ at $72{ }^{\circ} \mathrm{C}$ ). A melting curve was generated to confirm correct PCR amplification. Dilution factors for each individual DNA extract were used to calculate copy number/g based on total DNA amount in the $200 \mathrm{mg}$ sample.

Statistical analysis was carried out with SPSS 19.0 (SPSS Inc., IL, USA). The data was structured to address questions on overall effect, time effects as well as intestinal site. Thus, the data was grouped for overall effect (combining all days and all intestinal site data), grouped for time effects (data split into sampling day combining all intestinal sites) as well as for effects of intestinal site (data split into intestinal site combining all sampling days). Significant differences were determined by the Kruskal-Wallis test followed by the Mann-Whitney $\mathrm{U}$ test, where appropriate. Differences at $P<0.05$ were considered significant.

\section{Results and discussion}

This study was part of a larger feeding trial in which the impact of zinc oxide on microbiological $[2,3,6,7]$, morphological and immunological [10] as well as physiological [11] parameters were investigated. The interested reader is referred to these publications for a deeper analysis on the subject.

Overall, the combined data $(\mathrm{n}=336)$ showed a significant increase of copy numbers for tet $\mathrm{A}$ and sul 1 in the high zinc treatment compared to the low or intermediate zinc treatment (Table 1). This result is in line with data for tetracycline and sulfonamide resistant $E$. coli strains by Bednorz et al. [7]. Thus, this overall analysis shows that high doses of dietary zinc oxide increase tetracycline and sulfonamide resistance genes of Gram-negative bacteria in weaned pigs. The possible connection between 
Table 1 Overall effect of dietary zinc on the occurrence of tet $A$ and sul 1 genes in pigs $(n=336)$

\begin{tabular}{lll}
\hline Dietary Zn & \multicolumn{2}{l}{$\begin{array}{l}\text { Antibiotic resistance genes [log copy } \\
\text { number/g sample] }\end{array}$} \\
\cline { 2 - 3 } & tetA & sul1 \\
\hline Low Zn & $4.78( \pm 0.63)^{\mathrm{a}}$ & $5.43( \pm 0.63)^{\mathrm{a}}$ \\
Intermediate Zn & $4.94( \pm 0.59)^{\mathrm{a}}$ & $5.50( \pm 0.69)^{\mathrm{a}}$ \\
High Zn & $5.29( \pm 0.60)^{\mathrm{b}}$ & $5.82( \pm 0.52)^{\mathrm{b}}$ \\
\hline
\end{tabular}

Sampling days: $6,13,20$ or 27 days post-weaning (26 days); intestinal sites: stomach, mid-jejunum, terminal ileum, colon ascendens

$a, b$ Significantly different within a column ( $p \leq 0.05$; Mann-Whitney $U$ test)

zinc- and antibiotic resistance has already been noted for E. coli isolates from swine manure [12] and also for multi resistant Staphylococcus aureus isolates of porcine origin [13].

The occurrence of tetA and sul1 was time dependent (Fig. 1). No treatment effects were observed 1 week after weaning, but significant differences between low/ intermediate and high zinc treatment groups evolved 2 weeks (sul 1$)$ and 3 weeks $(\operatorname{tet} \mathrm{A})$ after weaning and remained on a higher level until the end of the trial (see also Additional file 1: Table S2). Considering the reduction of enterobacteria in the intestine during the post weaning phase in pigs [2], it can be expected that the ratio of antibiotic resistance carrying enterobacteria even increased. An ex vivo study with stomach and jejunum samples from the same animals has shown also that bacterial zinc resistance develops 2 week after weaning [14]. Furthermore, in that study enterobacteria were much less influenced by high zinc doses than other bacterial groups like clostridia and especially lactobacilli. Therefore, the lack of significant differences between diets 1 week after weaning may reflect a coupled development of zinc and antibiotic resistance over time. This has implications for the extent of dietary zinc supplementation. Although it is recognized that the main beneficial results occur up to 2 weeks after weaning [1], commercial use of high dietary zinc extends beyond this time frame, especially in Asia and the Americas [15-17].

The antibiotic resistance genes tet $\mathrm{A}$ and sul 1 differ in their modes of action. Resistance against tetracycline in the form of the tet $\mathrm{A}$ gene is active, because it leads to the expression of a membrane bound efflux protein that recognizes tetracycline [18]. On the other hand, sulfonamide resistance (sul1 gene) is passive as resistant bacteria develop sulfonamide insensitive dihydropteroate synthases [19]. Thus, different modes of action may have occurred for the antibiotic resistance gene development in the intestine of pigs. An increase of antibiotic resistance due to the presence of heavy metals such as $\mathrm{Hg}$,
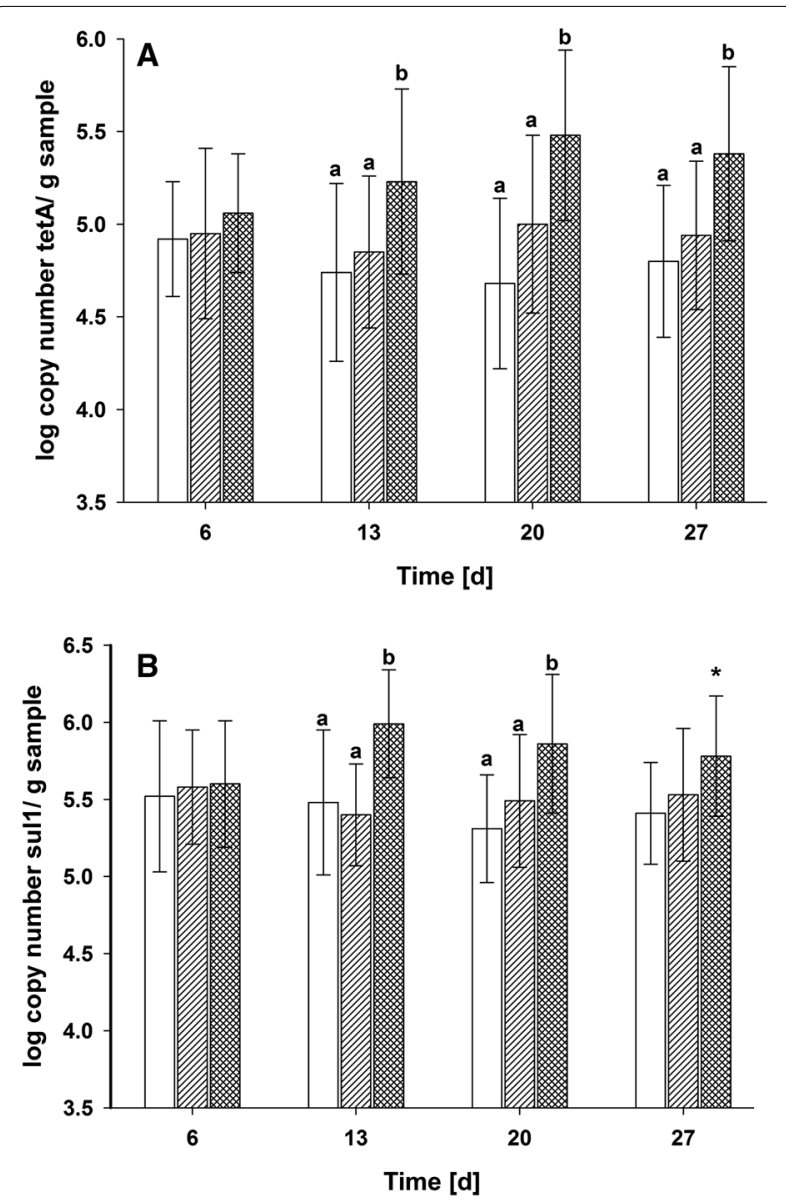

Fig. 1 Time dependent effect of antibiotic resistance development Combined data from all intestinal sites; open bar low dietary Zn; bar with diagonal lines intermediate dietary $\mathrm{Zn}$; hatched bar high dietary $Z n ;{ }^{a, b}$ Significantly different; ${ }^{*}=$ trend $(p<0.1)$ for difference to low and intermediate dietary Zn groups. a tetA gene; b sul1 gene

$\mathrm{Cd}, \mathrm{Cu}$ and $\mathrm{Zn}$ can take place via co-resistance or crossresistance [20]. Co-resistance is defined as the close proximity of two or more genetic elements encoding for resistances, while cross-resistance evolves when an antibacterial agent attacks the same target, for instance efflux systems that simultaneously transport two or more types of antibacterial agents [21].

In the case of tetracycline resistance, a cross-resistance mechanism may apply here, as zinc resistant strains would also expel tetracycline using the same efflux system. This is known for some bacteria regarding zinc and tetracycline resistance [22]. Sulfonamide resistance would rather follow the co-resistance path, as sulfonamides act as competitors of 4-aminobenzoate which is one of the substrates of dihydropteroate synthases. The enzyme is not known to be inhibited by zinc; on the contrary, it is an enzyme with zinc as cofactor [23]. 
Therefore, it is unlikely that zinc itself would have any influence on the development of sulfonamide resistance. Here, an increase via horizontal gene transfer is more likely the reason for an increased number of sul1 genes. This hypothesis was also put forward by Bednorz et al. [7]. Thus, multiple mechanisms may be involved in the development of antibiotic resistance in the porcine intestine due to the presence of zinc.

The presence of tetA and sul1 genes within the gastrointestinal tract was also addressed in this study. An analysis for gastro-intestinal sites revealed that significant differences between low/intermediate and high treatment groups occurred already in the stomach and continued throughout the intestinal tract (Fig. 2). The lowest copy numbers for each group were found in the small intestine. Pigs harbor a very metabolically active gastric microbiota during the first weeks after weaning, due to a comparably high $\mathrm{pH}$ in the stomach. Enterobacteria and even strict anaerobic bacterial groups can be found via
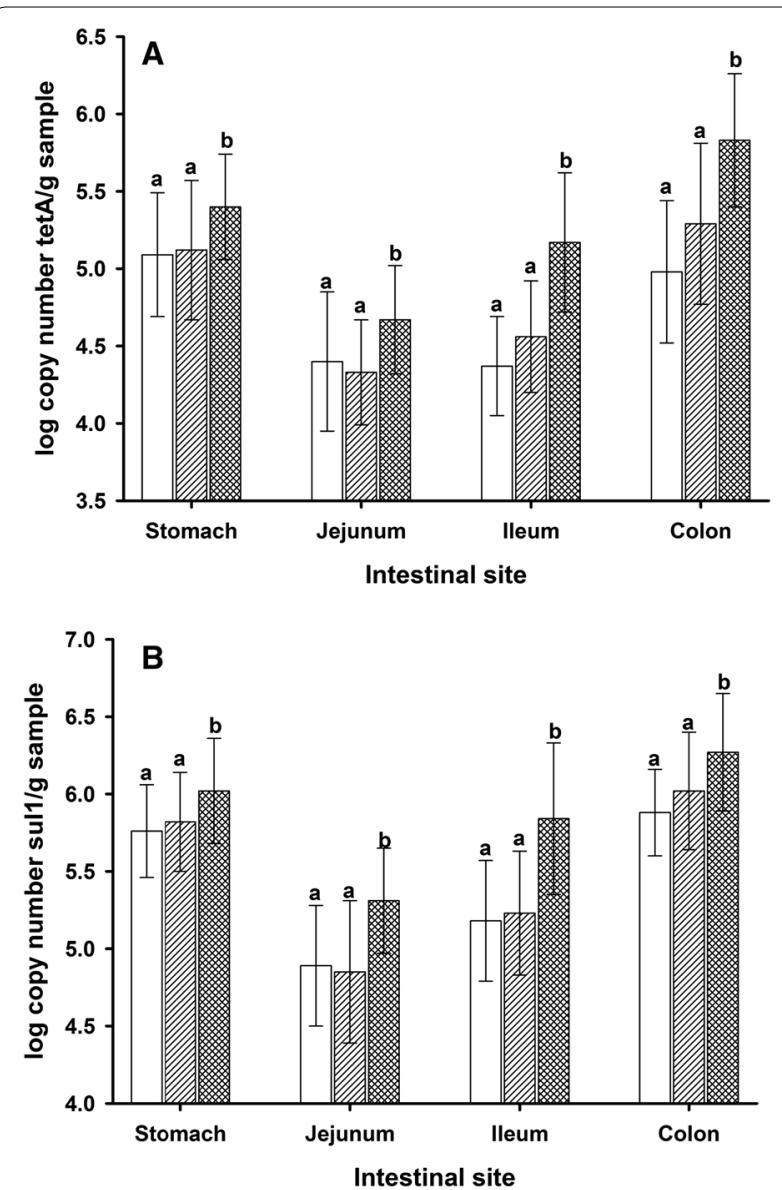

Fig. 2 Distribution of antibiotic resistance in the intestine of pigs. Combined data from all sampling days; open bar low dietary $\mathrm{Zn}$; bar with diagonal lines intermediate dietary Zn; hatched bar high dietary $\mathrm{Zn}$; ${ }^{\mathrm{a}, \mathrm{b}}$ Significantly different; $\mathbf{a}=$ tetA gene; $\mathbf{b}$ sul1 gene molecular methods in the stomach and small intestine $[2,24]$. A hypothesis put forward by our research group $[3,14]$ states that zinc ions are released already in the stomach, thereby modifying the microbiota that reaches the small and large intestine, because zinc oxide displays increased solubility at acidic $\mathrm{pH}$. Indeed, the ratio of free zinc ions to total zinc is highest in the stomach, followed by reduced ratios in the small intestine, while only very low concentrations of free zinc are observed in the large intestine [25]. Thus, high concentrations of dietary zinc may have the strongest impact in the stomach, generating zinc resistant enterobacteria which then "inoculate" the small and large intestine.

\section{Conclusions}

This study has shown that high doses of dietary zinc increase the number of tet $\mathrm{A}$ and $\operatorname{sul} 1$ gene copies in the gastrointestinal tract of pigs. Further studies on this topic are necessary to elucidate the molecular mechanisms and time frame of antibiotic resistance development. However, due to the time dependent development a use of high doses of dietary zinc beyond 2 weeks after weaning should be avoided in pigs because of the possible increase of antibiotic resistance in Gram-negative bacteria.

\section{Additional file}

Additional file 1. Strains used for validation of PCR assays for the detec tion of the tetA and sul1 gene.

\section{Authors' contributions}

DP carried out the molecular analysis and drafted the manuscript. IS participated in the molecular analysis and coordinated the experiment. WV participated in the design of the study, performed the statistical analysis and helped to draft the manuscript. JZ conceived of the study and helped to draft the manuscript. All authors read and approved the final manuscript.

\section{Compliance with ethical guidelines}

Competing interests

The authors declare that they have no competing interests.

Received: 8 June 2015 Accepted: 11 August 2015

Published online: 26 August 2015

\section{References}

1. Pettigrew JE (2006) Reduced use of antibiotic growth promoters in diets fed to weanling pigs; dietary tools, part 1. Anim Biotechnol 17:207-215

2. Starke IC, Pieper R, Neumann K, Zentek J, Vahjen W (2014) The impact of high dietary zinc oxide on the development of the intestinal microbiota in weaned piglets. FEMS Microbiol Ecol 87:416-427

3. Vahjen W, Pieper R, Zentek J (2010) Bar-coded pyrosequencing of $16 \mathrm{~S}$ rRNA gene amplicons reveals changes in ileal porcine bacterial communities due to high dietary zinc intake. Appl Environ Microbiol 76:6689-6691

4. Broom L, Miller HM, Kerr KG, Knapp JS (2006) Effects of zinc oxide and Enterococcus faecium SF68 dietary supplementation on the performance, intestinal microbiota and immune status of weaned piglets. Res Vet Sci 80:45-54 
5. Hojberg O, Canibe N, Poulsen HD, Hedemann MS, Jensen BB (2005) Influence of dietary zinc oxide and copper sulfate on the gastrointestinal ecosystem in newly weaned piglets. Appl Environ Microb 71:2267-2277

6. Vahjen W, Pieper R, Zentek J (2011) Increased dietary zinc oxide changes the bacterial core and enterobacterial composition in the ileum of piglets. J Anim Sci 89:2430-2439

7. Bednorz C, Oelgeschläger K, Kinnemann B, Hartmann S, Neumann K, Pieper R, Bethe A, Semmler T, Tedin K, Schierack P, Wieler LH, Guenther S (2013) The broader context of antibiotic resistance: zinc feed supplementation of piglets increases the proportion of multi-resistant Escherichia coli in vivo. Int J Med Microbiol 303:396-403

8. Burgos Y, Beutin L (2010) Common origin of plasmid encoded alphahemolysin genes in Escherichia coli. BMC Microbiol 10:193

9. Rayamajhi N, Cha SB, Kang ML, Lee SI, Lee HS, Yoo HS (2009) Inter- and intraspecies plasmid-mediated transfer of florfenicol resistance in Enterobacteriaceae isolates from swine. Appl Environ Microbiol 75:5700-5703

10. Liu P, Pieper R, Rieger J, Vahjen W, Davin R, Plendl J, Meyer W, Zentek $J$ (2014) Effect of dietary zinc oxide on morphological characteristics, mucin composition and gene expression in the colon of weaned piglets. PLoS One 9:e91091. doi:10.1371/journal.pone.0091091

11. Martin L, Pieper R, Schunter N, Vahjen W, Zentek J (2013) Performance, organ zinc concentration, jejunal brush border membrane enzyme activities and mRNA expression in piglets fed with different levels of dietary zinc. Arch Anim Nutr 67:248-261

12. Holzel CS, Muller C, Harms KS, Mikolajewski S, Schafer S, Schwaiger K, Bauer J (2012) Heavy metals in liquid pig manure in light of bacterial antimicrobial resistance. Environ Res 113:21-27

13. Cavaco LM, Hasman H, Aarestrup FM (2011) Zinc resistance of Staphylococcus aureus of animal origin is strongly associated with methicillin resistance. Vet Microbiol 150:344-348

14. Starke IC, Zentek J, Vahjen W (2013) Ex vivo-growth response of porcine small intestinal bacterial communities to pharmacological doses of dietary zinc oxide. PLoS One 8:e56405. doi:10.1371/journal.pone.0056405
15. Anonymous. The pigSite, Pig health: Zinc. Quote: Occasionally the withdrawal of the zinc two to three weeks after weaning can result in diarrhoea and in such cases it may be necessary to continue its use for a further two to three weeks. http://www.thepigsite.com/pighealth/article/546/zinc. Accessed 10 July 2015

16. Jacela JY, DeRouchey JM, Tokach MD, Goodband RD, Nelssen JL, Renter DG, Dritz SS (2010) Feed additives for swine: fact sheets-high dietary levels of copper and zinc for young pigs, and phytase. J Swine Health Prod 18:87-91

17. Durosoy S. President of Anime, Sillingy, France. (2014) Personal communication on the use of zinc oxide in pig nutrition. Contact: sdurosoy@ animine.eu

18. Speer BS, Shoemaker NB, Salyers AA (1992) Bacterial resistance to tetracycline: mechanisms, transfer, and clinical significance. Clin Microbiol Rev 5:387-399

19. Sköld O (2001) Resistance to trimethoprim and sulfonamides. Vet Res 32:261-273

20. Seiler C, Berendonk TU (2006) Heavy metal driven co-selection of antibiotic resistance in soil and water bodies impacted by agriculture and aquaculture. Front Microbiol 3:399

21. Baker-Austin C, Wright MS, Stepanauskas R, McArthur JV (2006) Coselection of antibiotic and metal resistance. Trends Microbiol 14:176-182

22. Silver S (1996) Bacterial heavy metal resistance: new surprises. Ann Rev Microb 50:753-789

23. Suckling CJ, Sweeney JR, Wood HC (1977) Dihydropteroate synthase: purification by affinity chromatography and mechanism of action. J Chem Soc Perk 4:439-442

24. Leser TD, Amenuvor JZ, Jensen TK, Lindecrona RH, Boye M, Møller K (2002) Culture-independent analysis of gut bacteria: the pig gastrointestinal tract microbiota revisited. Appl Environ Microbiol 68:673-690

25. Dintzis FR, Laszlo JA, Nelsen TC, Baker FL, Calvert CC (1995) Free and total ion concentrations in pig digesta. J Anim Sci 73:1138-1146

\section{Submit your next manuscript to BioMed Central and take full advantage of:}

- Convenient online submission

- Thorough peer review

- No space constraints or color figure charges

- Immediate publication on acceptance

- Inclusion in PubMed, CAS, Scopus and Google Scholar

- Research which is freely available for redistribution

Submit your manuscript at

www.biomedcentral.com/submit

C Biomed Central 